\title{
Evaluation of a Nasal Cannula in Noninvasive Ventilation Using a Lung Simulator
}

\author{
Narayan P Iyer MD and Robert Chatburn MHHS RRT-NPS FAARC
}

\begin{abstract}
BACKGROUND: Nasal noninvasive ventilation (NIV) is a common form of noninvasive respiratory mode used in newborn infants. A next-generation nasal cannula (Neotech RAM cannula) has recently been used to provide nasal NIV. The impact of the Neotech RAM cannula on the delivery of pressure needs to be studied. METHODS: In this ex vivo experimental design, a lung simulator (IngMar ASL 5000, version 3.4) was programmed to model a neonate ( $\sim 1-3 \mathrm{~kg}$ of body weight) with normal-to-moderately affected lungs. We used a Covidien PB840 ventilator with NIV software activated to compensate for leaks. Nasal NIV was set at peak airway pressures of 15, 20, and $25 \mathrm{~cm} \mathrm{H} \mathrm{H}_{2} \mathrm{O}$ and PEEP of 5, 6, and $7 \mathrm{~cm} \mathrm{H}_{2} \mathrm{O}$. Three sizes of the Neotech RAM cannula were used (prong outer diameters of 3.0,3.5, and $4.0 \mathrm{~mm}$ ). The nose was designed to keep the leak of the nares by the prongs to $30 \%$. We also created a worst case leak ( $58 \%$ leak) by using the largest simulated nostril diameter with the smallest diameter Neotech RAM cannula prong. The outcome measure was the difference in pressures, referred to as leak effect, measured by the lung simulator relative to the set peak airway pressure and PEEP on the ventilator. RESULTS: For the interface with 30\% leak, leak effects of peak airway pressure during simulated nasal NIV were similar with all Neotech RAM cannula sizes, with 63-75\% of peak airway pressure and 70-90\% of PEEP being transmitted across the nasal interface. The worst case scenario produced a $92 \%$ leak effect in peak airway pressure and PEEP. CONCLUSIONS: When used with $\leq 30 \%$ leak, the Neotech RAM cannula interface results in clinically acceptable transmission of pressures. With $>\mathbf{5 0 \%}$ leak, a clinically negligible amount of pressure is transmitted to the artificial lungs. Key words: noninvasive ventilation; bronchopulmonary dysplasia; lung distending pressure; nasal cannula; RAM cannula. [Respir Care 2015;60(4):508-512. (C) 2015 Daedalus Enterprises]
\end{abstract}

\section{Introduction}

Noninvasive ventilatory support is the mainstay of respiratory management in preterm infants. Nasal intermit-

\footnotetext{
Dr Iyer is affiliated with the Division of Neonatology, Department of Pediatrics, MetroHealth Medical Center, Case Western Reserve University, Cleveland, Ohio. Mr Chatburn is affiliated with the Respiratory Institute, Cleveland Clinic, and the Department of Medicine, Lerner College of Medicine of Case Western Reserve University, Cleveland, Ohio.

Neotech supplied cannulas and artificial nose fixtures. Mr Chatburn has disclosed relationships with Neotech and IngMar Medical.

Correspondence: Robert Chatburn MHHS RRT FAARC, Cleveland Clinic, M-56, 9500 Euclid Avenue, Cleveland, OH 44121. E-mail: chatbur@ccf.org.
}

DOI: $10.4187 /$ respcare. 03560 tent positive-pressure ventilation, a form of nasal noninvasive ventilation (NIV), is a common form of noninvasive ventilatory support in very low birthweight infants. The main aims of nasal NIV are to reduce the frequency of apnea, extubation failure, and bronchopulmonary dysplasia. ${ }^{1-4}$ By providing a continuous distending pressure and intermittent breaths, nasal NIV devices are supposed to improve tidal volumes $\left(\mathrm{V}_{\mathrm{T}}\right)$, reduce the work of breathing, improve oxygenation, and increase carbon dioxide elimination. ${ }^{5,6}$ Nasal NIV is delivered by a variety of devices that generate either a preset flow or a preset pressure to the nares. Flow generators (eg, Infant Flow SiPAP system, CareFusion, San Diego, California) maintain a constant flow through the system and develop pressure as a back pressure in proportion to the set flow and impedance of an infant's respiratory system. In the bi-level mode, SiPAP provides 2 levels of CPAP and is supposed to augment the functional residual capacity. ${ }^{7}$ Conventional mechanical 
ventilators are also used in pressure control modes, particularly when an NIV feature is available. This feature allows for compensation of the expected leaks when using NIV interfaces such as CPAP prongs or high-flow nasal cannulas. This diversity of machines is, in part, responsible for considerable intrapatient and interpatient variation in the effectiveness of noninvasive respiratory support. ${ }^{8,9}$ A next-generation nasal cannula (RAM cannula, Neotech, Valencia, California) has recently been used as an interface to provide noninvasive ventilatory support, such as nasal intermittent positive-pressure ventilation, CPAP, and noninvasive neurally adjusted ventilatory assist. ${ }^{10}$ The impact of the Neotech RAM cannula on the delivery of pressure and $V_{T}$ needs to be studied to allow clinicians and therapists to use the cannula effectively.

The main purpose of this study was to determine the relation between set and delivered pressures during NIV of a lung simulator using the Neotech RAM cannula.

\section{Methods}

\section{Study Design}

We used an ex vivo experimental design with a lung simulator and plastic fixtures to represent the infant nose (3 sizes).

\section{Equipment and Settings}

An ASL 5000 lung simulator (version 3.4, IngMar Medical, Pittsburgh, Pennsylvania) was programmed to model a neonate ( $\sim 1-3 \mathrm{~kg}$ of body weight) with normal-to-moderately affected lungs ${ }^{11}$ : compliance, $1.5 \mathrm{~mL} / \mathrm{cm} \mathrm{H}_{2} \mathrm{O}$; resistance, $70 \mathrm{~cm} \mathrm{H}_{2} \mathrm{O} / \mathrm{L} / \mathrm{s}$; and maximum simulated muscle pressure, zero (passive model).

Data from a previous study ${ }^{12}$ were used for choosing ventilator settings: ventilator, PB840 ventilator (Covidien, Mansfield, Massachusetts) with mode set to pressure control continuous mandatory ventilation with noninvasive leak compensation active; peak airway pressure (above atmospheric pressure), 15, 20, and $25 \mathrm{~cm} \mathrm{H}_{2} \mathrm{O}$; PEEP during CPAP mode, 5, 6, and $7 \mathrm{~cm} \mathrm{H}_{2} \mathrm{O}$; breathing frequency, 40 breaths/min; and inspiratory time, $0.5 \mathrm{~s}$. The lung simulator calculated the mean values from 10 breaths in each experimental condition.

The are 3 sizes of the Neotech RAM cannula currently available, with prong outer diameters of $3.0 \mathrm{~mm}$ (preemie), $3.5 \mathrm{~mm}$ (newborn), and $4.0 \mathrm{~mm}$ (infant). Cannula sizes are selected using a template intended to match the prong size to the approximate patient size in terms of nostril diameter. The template is designed so that the crosssectional area of the Neotech RAM cannula prongs is $\sim 70 \%$ of the cross-sectional area of the nostrils (ie, $\sim 70 \%$ occlusion).

\section{QUICK LOOK}

\section{Current knowledge}

Noninvasive ventilation via the nasal route is a common form of noninvasive ventilatory support in newborn infants. A number of nasal interfaces have been used for support, including a specially designed nasal cannula.

\section{What this paper contributes to our knowledge}

Using a next-generation cannula interface in a model system, with a properly sized cannula-to-nasal diameter, resulted in transmission of $60-70 \%$ of the set peak airway pressure and PEEP. When the cannula size was too small relative to the nasal model diameter, pressure transmission was significantly reduced, resulting in a minimal amount of pressure being applied to the model.

The nose was simulated with a fixture created with a 3 -dimensional printer. The fixture was attached to a standard 22-15-mm adapter for connecting to the lung simulator (Fig. 1). The fixture was not intended to reproduce actual anatomic contours but rather simply to provide a convenient and realistic connection between the nasal cannula and lung simulator. Three fixtures were made with nostril diameters of $3.4,4.0$, and $4.6 \mathrm{~mm}$ (same as the cannula sizing template and corresponding to the cannula sizes).
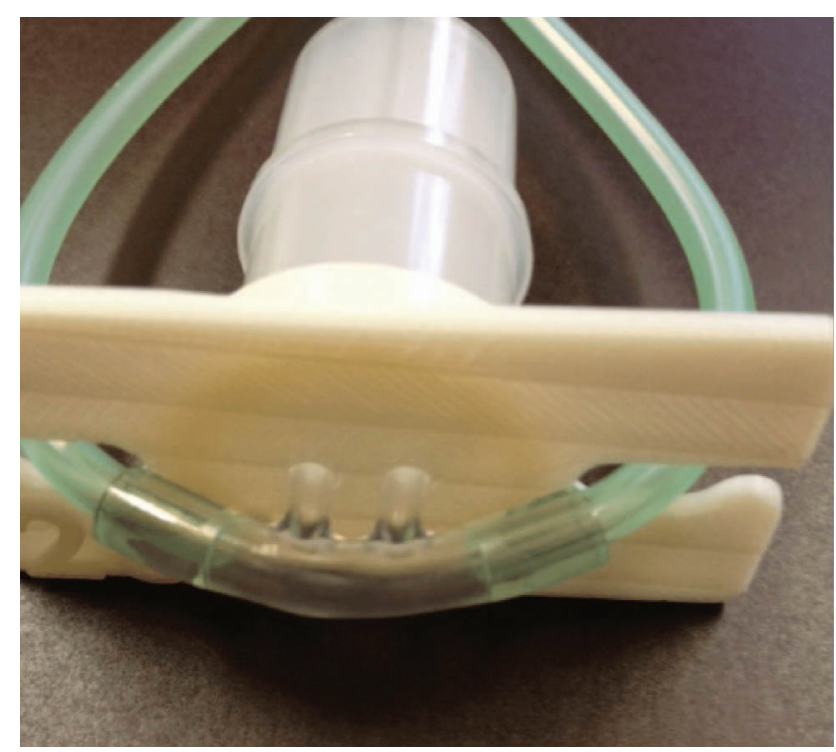

Fig. 1. Nasal fixture. 
Table 1. Measured Peak Airway Pressure in a Simulated Nose at Different Set Peak Airway Pressures

\begin{tabular}{|c|c|c|c|c|c|c|c|c|}
\hline & \multirow{2}{*}{$\begin{array}{l}\text { Cannula } \\
\text { Size } \\
(\mathrm{mm})\end{array}$} & \multirow{2}{*}{$\begin{array}{l}\text { Nostril } \\
\text { Size } \\
(\mathrm{mm})\end{array}$} & \multicolumn{3}{|c|}{ Measured Peak Airway Pressure $\left(\mathrm{cm} \mathrm{H}_{2} \mathrm{O}\right)$} & \multicolumn{3}{|c|}{ Leak Effect (\%) } \\
\hline & & & $\begin{array}{c}15 \mathrm{~cm} \mathrm{H}_{2} \mathrm{O} \text { Set } \\
\text { Peak Airway } \\
\text { Pressure }\end{array}$ & $\begin{array}{c}20 \mathrm{~cm} \mathrm{H}_{2} \mathrm{O} \text { Set } \\
\text { Peak Airway } \\
\text { Pressure }\end{array}$ & $\begin{array}{c}25 \mathrm{~cm} \mathrm{H}_{2} \mathrm{O} \text { Set } \\
\text { Peak Airway } \\
\text { Pressure }\end{array}$ & $\begin{array}{c}15 \mathrm{~cm} \mathrm{H}_{2} \mathrm{O} \text { Set } \\
\text { Peak Airway } \\
\text { Pressure }\end{array}$ & $\begin{array}{c}20 \mathrm{~cm} \mathrm{H}_{2} \mathrm{O} \mathrm{Set} \\
\text { Peak Airway } \\
\text { Pressure }\end{array}$ & $\begin{array}{c}25 \mathrm{~cm} \mathrm{H}_{2} \mathrm{O} \text { Set } \\
\text { Peak Airway } \\
\text { Pressure }\end{array}$ \\
\hline Preemie & 3.0 & 3.4 & 10.0 & 13.0 & 15.8 & -33 & -35 & -37 \\
\hline Newborn & 3.5 & 4.0 & 10.0 & 13.2 & 16.0 & -33 & -34 & -36 \\
\hline Infant & 4.0 & 4.6 & 11.3 & 14.9 & 18.3 & -25 & -26 & -27 \\
\hline Worst case & 3.0 & 4.6 & 1.3 & 1.7 & 2.2 & -91 & -92 & -91 \\
\hline
\end{tabular}

\section{Leak Conditions}

Four leak conditions were simulated: 3 normal leaks (representing appropriate cannula size selection) and 1 worst case leak (representing inappropriate sizing of the cannula). The normal leaks were created using the 3 sizes of the Neotech RAM cannula with their 3 recommended nares sizes as determined using the sizing template. The worst case leak ( $\sim 58 \%$ leak) was created by using the largest simulated nostril diameter from the sizing template $(4.6 \mathrm{~mm})$ with the smallest diameter cannula prong $(3.0 \mathrm{~mm})$. This was considered the worst case scenario in the sense that it is the most inappropriate fit possible using the available cannula sizes and the sizing template.

\section{Outcome Measures}

Pressures transmitted from the ventilator to the simulated nose were recorded by the ASL 5000 lung simulator (called mouth pressure by the software). Pressure waveforms were analyzed using the Post-Analysis software of the lung simulator. Peak airway pressures and PEEP values from these waveforms represented the true ventilating pressures as opposed to the set pressures read on the ventilator. The outcome was the difference in peak airway pressure and PEEP, referred to as leak effect, measured by the lung simulator (ie, the delivered true values) relative to the set peak airway pressure and PEEP on the ventilator. This difference was expressed as a percent leak effect relative to the ventilator setting: \% leak effect $=(($ measured pressure - set pressure)/set pressure) $\times 100 \%$. Thus, negative leak effect values indicate that the measured pressure was less than the set pressure.

We also measured the mean airway pressure and $\mathrm{V}_{\mathrm{T}}$ generated in the artificial lungs. Flow and volumes are measured internally in the ASL 5000 unit, and no external sensors are used for this purpose.

\section{Statistical Analysis}

We present descriptive statistics as mean values only. Because these mean values were calculated from several nearly identical breaths on a passive lung model, the SD was virtually zero (ie, $<0.02 \mathrm{~cm} \mathrm{H}_{2} \mathrm{O}$, well below the measurement error of a ventilator pressure display).

\section{Results}

For all experimental conditions, the actual pressures generated in the simulated nose were less than the pressures set on the ventilator (hence, leak effect values are negative), as shown in Table 1. Table 1 indicates that leak effects of peak airway pressure during simulated nasal NIV were similar across sizes, but were slightly higher for the preemie cannula and lowest $(\sim 25 \%)$ for the infant cannula. The worst case scenario (preemie cannula with infant nares) produced a $92 \%$ leak effect in peak airway pressure.

This order of magnitude for leak effect was the same for PEEP leak effect (Table 2), although the absolute values were different (range of $10-92 \%$ ). We are unable to explain the variation in the measured PEEP while using the newborn cannula. The other cannula sizes showed a trend of increasing percentage leak effect with increasing PEEP.

Mean airway pressure increased linearly with the increase in set peak pressure as shown in Table 3. We could not record the mean airway pressure for the worst case scenario.

The $\mathrm{V}_{\mathrm{T}}$ also increased with the increase in peak pressures and ranged from 13 to $29.6 \mathrm{~mL}$ (Table 4). $\mathrm{V}_{\mathrm{T}}$ in the worst case was very small and ranged from 1.9 to $3.1 \mathrm{~mL}$.

\section{Discussion}

Clinicians need to recognize the effectiveness and limitations of newer devices and interfaces, such as the Neotech RAM cannula, particularly when used in novel applications. In this simulation-based experiment, we evaluated the use of the Neotech RAM cannula in nasal NIV. Our results show that transmission of pressure across the nasal interface is dependent on the leak at the interface, with good pressure transmission when the nasal cannula is prop- 
Table 2. Measured PEEP in a Simulated Nose at Different PEEP Settings

\begin{tabular}{|c|c|c|c|c|c|c|c|c|}
\hline & \multirow{2}{*}{$\begin{array}{l}\text { Cannula Size } \\
(\mathrm{mm})\end{array}$} & \multirow{2}{*}{$\begin{array}{l}\text { Nostril Size } \\
\quad(\mathrm{mm})\end{array}$} & \multicolumn{3}{|c|}{ Measured PEEP $\left(\mathrm{cm} \mathrm{H}_{2} \mathrm{O}\right)$} & \multicolumn{3}{|c|}{ Leak Effect (\%) } \\
\hline & & & $\begin{array}{l}5 \mathrm{~cm} \mathrm{H}_{2} \mathrm{O} \\
\text { Set PEEP }\end{array}$ & $\begin{array}{l}6 \mathrm{~cm} \mathrm{H}_{2} \mathrm{O} \\
\text { Set PEEP }\end{array}$ & $\begin{array}{l}7 \mathrm{~cm} \mathrm{H}_{2} \mathrm{O} \\
\text { Set PEEP }\end{array}$ & $\begin{array}{l}5 \mathrm{~cm} \mathrm{H}_{2} \mathrm{O} \\
\text { Set PEEP }\end{array}$ & $\begin{array}{l}6 \mathrm{~cm} \mathrm{H}_{2} \mathrm{O} \\
\text { Set PEEP }\end{array}$ & $\begin{array}{l}7 \mathrm{~cm} \mathrm{H}_{2} \mathrm{O} \\
\text { Set PEEP } \\
\end{array}$ \\
\hline Preemie & 3.0 & 3.4 & 4.1 & 4.2 & 4.8 & -18 & -30 & -31 \\
\hline Newborn & 3.5 & 4.0 & 4.0 & 5.1 & 5.8 & -20 & -15 & -17 \\
\hline Infant & 4.0 & 4.6 & 4.5 & 5.1 & 5.7 & -10 & -15 & -19 \\
\hline Worst case & 3.0 & 4.6 & 0.4 & 0.6 & 0.7 & -92 & -90 & -90 \\
\hline
\end{tabular}

All values are averages. SD was virtually zero $\left(<0.02 \mathrm{~cm} \mathrm{H}_{2} \mathrm{O}\right)$ due to the nature of the simulation.

Table 3. Measured $\overline{\mathrm{P}}_{\mathrm{aw}}$ in a Simulated Nose at Different Set Peak Airway Pressures

\begin{tabular}{|c|c|c|c|c|c|}
\hline & \multirow[b]{2}{*}{$\begin{array}{c}\text { Cannula } \\
\text { Size } \\
(\mathrm{mm})\end{array}$} & \multirow[b]{2}{*}{$\begin{array}{l}\text { Nostril } \\
\text { Size } \\
(\mathrm{mm})\end{array}$} & \multicolumn{3}{|c|}{ Measured $\overline{\mathrm{P}}_{\mathrm{aw}}\left(\mathrm{cm} \mathrm{H}_{2} \mathrm{O}\right)$} \\
\hline & & & $\begin{array}{c}15 \mathrm{~cm} \mathrm{H}_{2} \mathrm{O} \\
\text { Set Peak } \\
\text { Airway } \\
\text { Pressure }\end{array}$ & $\begin{array}{c}20 \mathrm{~cm} \mathrm{H}_{2} \mathrm{O} \\
\text { Set Peak } \\
\text { Airway } \\
\text { Pressure }\end{array}$ & $\begin{array}{c}25 \mathrm{~cm} \mathrm{H}_{2} \mathrm{O} \\
\text { Set Peak } \\
\text { Airway } \\
\text { Pressure }\end{array}$ \\
\hline Preemie & 3.0 & 3.4 & 6.4 & 7.5 & 8.5 \\
\hline Newborn & 3.5 & 4.0 & 6.3 & 7.4 & 8.5 \\
\hline Infant & 4.0 & 4.6 & 7.0 & 8.3 & 9.6 \\
\hline Worst case & 3.0 & 4.6 & $\approx 0$ & $\approx 0$ & $\approx 0$ \\
\hline
\end{tabular}

$\overline{\text { All values are averages. }}$ SD was virtually zero $\left(<0.02 \mathrm{~cm} \mathrm{H}_{2} \mathrm{O}\right)$ due to the nature of the simulation.

$\overline{\mathrm{P}}_{\mathrm{aw}}=$ mean airway pressure

Table 4. Measured $\mathrm{V}_{\mathrm{T}}$ in Simulated Lungs at Different Set Peak Airway Pressures

\begin{tabular}{|c|c|c|c|c|c|}
\hline & \multirow[b]{2}{*}{$\begin{array}{l}\text { Cannula } \\
\text { Size } \\
(\mathrm{mm})\end{array}$} & \multirow[b]{2}{*}{$\begin{array}{l}\text { Nostril } \\
\text { Size } \\
(\mathrm{mm})\end{array}$} & \multicolumn{3}{|c|}{ Measured $\mathrm{V}_{\mathrm{T}}(\mathrm{mL})$} \\
\hline & & & $\begin{array}{c}15 \mathrm{~cm} \mathrm{H}_{2} \mathrm{O} \\
\text { Set Peak } \\
\text { Airway } \\
\text { Pressure }\end{array}$ & $\begin{array}{c}20 \mathrm{~cm} \mathrm{H}_{2} \mathrm{O} \\
\text { Set Peak } \\
\text { Airway } \\
\text { Pressure }\end{array}$ & $\begin{array}{c}25 \mathrm{~cm} \mathrm{H}_{2} \mathrm{O} \\
\text { Set Peak } \\
\text { Airway } \\
\text { Pressure }\end{array}$ \\
\hline Preemie & 3.0 & 3.4 & 13.0 & 19.0 & 25.6 \\
\hline Newborn & 3.5 & 4.0 & 13.0 & 19.7 & 26.0 \\
\hline Infant & 4.0 & 4.6 & 14.7 & 22.0 & 29.6 \\
\hline Worst case & 3.0 & 4.6 & 1.9 & 2.6 & 3.1 \\
\hline \multicolumn{6}{|c|}{$\begin{array}{l}\text { All values are averages. standard deviations were virtually zero }(<0.02 \mathrm{ml}) \text { due to the nature } \\
\text { of the simulation. } \\
\mathrm{V}_{\mathrm{T}}=\text { tidal volume }\end{array}$} \\
\hline
\end{tabular}

erly sized using a template, but with very little transmission when sizing is inappropriate.

There was loss of $25-37 \%$ of peak pressure across the interface for different settings. We speculate that this degree of inspiratory pressure leak effect may be clinically acceptable in terms of providing ventilatory support to infants represented by our lung model parameters (ie, weighing $1-3 \mathrm{~kg}$ with normal lungs or moderate lung dis- ease). We base this speculation on the fact that $\mathrm{V}_{\mathrm{T}}$ delivered by the actual nasal pressure changes was on the order of 13-29 mL. These volumes would be considered satisfactory to high for most newborn infants. However, in studies on newborn infants, synchronized delivery of nasal intermittent positive-pressure ventilation either did not change or minimally changed $\mathrm{V}_{\mathrm{T}}$ delivery. Reasons for this discrepancy are, for now, unknown. ${ }^{5,13}$ Given that this was a passive model and that NIV is virtually always applied to patients who can sustain some degree of inspiratory effort, the level of support given to a real patient using these cannula sizes would be appropriate with minor ventilator adjustments. Measured PEEP levels during simulated nasal NIV were also acceptable.

The data for the worst case scenario (smallest prongs and largest nares diameter) indicate the importance of correct sizing of prongs to the patient's actual nasal dimensions during NIV using a nasal cannula as the patientventilator interface (eg, as opposed to a tight-fitting mask). This implies the need for clear and detailed product information and adequate clinician training. The data from this study also highlight the importance of appropriate sizing template dimensions. We conclude that the sizing template used in the study (which assumes a 70\% occlusion based on relative areas of nostril and nasal prong) is appropriate.

Our study has limitations. Lung simulator-based studies represent the best case scenario and do not account for the variability associated with daily use, such as a nasal cannula being loose-fitting or partially out or blocked with secretions. However, lung simulator studies, such as ours, inform us about the physical properties associated with the nasal cannula interface with a high level of accuracy and reliability. The lung simulator simply provided a load with values of resistance and compliance for the respiratory system that are representative of a particular size neonate. The actual values are relatively unimportant because of the high variability of mechanical properties, including highly variable inspiratory/expiratory efforts. The point of using a passive simulation is to highlight the basic physics of the patient-ventilator system under ideal conditions to help understand the clinical implications of a nasal cannula for 


\section{Neonatal Nasal Cannula for NIV}

NIV. Our results are not intended to guide setting of inspiratory pressure on the ventilator. The relationship between set inspiratory pressure and the pressure/volume delivered to the lungs in an actual clinical situation is dependent on many uncontrollable factors, which is why NIV, in general, and NIV through nasal prongs, in particular, are exercises in rough estimates at best. The leak compensation option (ie, using the noninvasive feature) on the PB840 ventilator is designed to compensate for leaks in the breathing circuit to maintain PEEP and prevent autotriggering during NIV and invasive ventilation. It is possible that not using the leak compensation for this experiment or using a different ventilator that does not offer leak compensation may have yielded different results. Further study of this issue is warranted.

In conclusion, when properly sized to nasal diameter, the Neotech RAM cannula interface results in transmission of $60-70 \%$ of the set peak airway pressure and PEEP. When the cannula size is not appropriate, the resulting pressure transmission is drastically reduced, resulting in a clinically negligible amount of pressure being applied to the artificial lungs.

\section{REFERENCES}

1. Khalaf MN, Brodsky N, Hurley J, Bhandari V. A prospective randomized, controlled trial comparing synchronized nasal intermittent positive pressure ventilation versus nasal continuous positive airway pressure as modes of extubation. Pediatrics 2001;108(1):13-17.

2. Barrington KJ, Bull D, Finer NN. Randomized trial of nasal synchronized intermittent mandatory ventilation compared with continuous positive airway pressure after extubation of very low birth weight infants. Pediatrics 2001;107(4):638-641.

3. Bhandari V, Gavino RG, Nedrelow JH, Pallela P, Salvador A, Ehrenkranz RA, Brodsky NL. A randomized controlled trial of syn- chronized nasal intermittent positive pressure ventilation in RDS. J Perinatol 2007;27(11):697-703.

4. Lemyre B, Davis PG, de Paoli AG. Nasal intermittent positive pressure ventilation (NIPPV) versus nasal continuous positive airway pressure (NCPAP) for apnea of prematurity. Cochrane Database Syst Rev 2002(1):CD002272.

5. Owen LS, Morley CJ, Dawson JA, Davis PG. Effects of non-synchronised nasal intermittent positive pressure ventilation on spontaneous breathing in preterm infants. Arch Dis Child Fetal Neonatal Ed 2011;96(6):F422-F428.

6. Moretti C, Gizzi C, Papoff P, Lampariello S, Capoferri M, Calcagnini G, Bucci G. Comparing the effects of nasal synchronized intermittent positive pressure ventilation (nSIPPV) and nasal continuous positive airway pressure (nCPAP) after extubation in very low birth weight infants. Early Hum Dev 1999;56(2-3):167-177.

7. Lista G, Castoldi F, Fontana P, Daniele I, Cavigioli F, Rossi S, et al. Nasal continuous positive airway pressure (CPAP) versus bi-level nasal CPAP in preterm babies with respiratory distress syndrome: a randomised control trial. Arch Dis Child Fetal Neonatal Ed 2010; 95(2):F85-F89.

8. Cook SE, Fedor KL, Chatburn RL. Effects of imposed resistance on tidal volume with 5 neonatal nasal continuous positive airway pressure systems. Respir Care 2010;55(5):544-548.

9. Volsko TA, Fedor K, Amadei J, Chatburn RL. High flow through a nasal cannula and CPAP effect in a simulated infant model. Respir Care 2011;56(12):1893-1900.

10. Nzegwu NI, Mack T, DellaVentura R, Dunphy L, Koval N, Levit O, Bhandari V. Systematic use of the RAM nasal cannula in the YaleNew Haven Children's Hospital Neonatal Intensive Care Unit: a quality improvement project. J Matern Fetal Neonatal Med 2014;1-4.

11. Sivieri EM, Gerdes JS, Abbasi S. Effect of HFNC flow rate, cannula size, and nares diameter on generated airway pressures: an in vitro study. Pediatr Pulmonol 2013;48(5):506-514.

12. Bhandari $\mathrm{V}$. Nasal intermittent positive pressure ventilation in the newborn: review of literature and evidence-based guidelines. J Perinatol 2010;30(8):505-512.

13. Chang HY, Claure N, D'ugard C, Torres J, Nwajei P, Bancalari E. Effects of synchronization during nasal ventilation in clinically stable preterm infants. Pediatr Res 2011;69(1):84-89.

This article is approved for Continuing Respiratory Care Education credit. For information and to obtain your CRCE

(free to AARC members) visit www.rcjournal.com 